\title{
Etifoxine does not impair muscle tone and motor function in rats as assessed by in vivo and in vitro methods
}

\author{
Vesela Yu. Kokova ${ }^{1}$, Plamen I. Zagorchev ${ }^{2}$, Elisaveta G. Apostolova ${ }^{1}$ and Lyudmil P. Peychev ${ }^{1}$ \\ ${ }^{1}$ Department of Pharmacology and Drug Toxicology, Faculty of Pharmacy, Medical University-Plovdiv, Bulgaria \\ ${ }^{2}$ Department of Medical Physics and Biophysics, Faculty of Pharmacy, Medical University-Plovdiv, Bulgaria
}

\begin{abstract}
The purpose of our study is to evaluate the effects of the translocator protein (TSPO) ligand etifoxine on muscle tone and locomotor activity. In addition, the mechanism of action of etifoxine on the presynaptic membrane and neuromuscular junction is investigated. These effects of etifoxine were examined employing the following methods: 1 ) in vivo experiments using bar holding test and activity cage test, and 2) comparative in vitro studies with nifedipine on indirectly-elicited twitches of striated abdominal muscle preparations. Etifoxine in doses $50 \mathrm{mg} / \mathrm{kg}$ and $100 \mathrm{mg} / \mathrm{kg}$ i.p. does not produce any significant changes in locomotor activity and muscle tone of intact rats. Nifedipine $\left(10^{-5} \mathrm{M}\right)$ induces a significant decrease in the muscle force of striated muscle preparations. Etifoxine $\left(10^{-8}-10^{-4} \mathrm{M}\right)$ has no significant effect on indirectly-elicited twitch tension. Results show that the TSPO ligand etifoxine has no myorelaxant effect. The activation of TSPO is not associated with a reduction in muscle tone and motor impairment. Etifoxine does not affect the presynaptic membrane and its influence on L-type $\mathrm{Ca}^{2+}$-channels is insignificant. Etifoxine does not act as a competitive antagonist of acetylcholine and does not impair the impulse transmission in the neuromuscular junction.
\end{abstract}

Key words: Etifoxine - TSPO — Nifedipine — Indirectly-elicited twitches — Striated muscle

\section{Introduction}

Etifoxine is a non-benzodiazepine anxiolytic drug, which also possesses an anticonvulsant effect. Etifoxine potentiates GABAergic neurotransmission by a dual mode of action: 1) a direct positive allosteric effect on $\mathrm{GABA}_{\mathrm{A}}$ receptors, and 2) an indirect mechanism involving the stimulation of translocator protein (TSPO) with subsequent influence on neurosteroid synthesis (Schlichter et al. 2000).

Etifoxine is used in the clinical practice for treatment of anxiety disorders. Clinical trials reported similar efficacy of etifoxine and buspirone (Servant et al. 1998), phenazepam (Aleksandrovsky et al. 2010), and lorazepam (Micallef et al. 2001; Nguyen et al. 2006) in adjustment disorder with anxiety (ADWA). The conventional benzodiazepine anxiolytics possess side effects, such as a potential risk of cognitive dysfunction, dependence, myorelaxation, etc. Due to its

Correspondence to: Vesela Yulieva Kokova, Department of Pharmacology and Drug Toxicology, Faculty of Pharmacy, Medical University-Plovdiv, 15A Vassil Aprilov Blvd. 4002 Plovdiv, Bulgaria E-mail: vesela_uk@abv.bg specific mechanism of action, etifoxine has reduced cognitive effects and does not induce amnesia and sedation at anxiolytic concentrations (Micallef et al. 2001). Moreover, treatment with etifoxine is not associated with dependence and psychomotor adverse effects (Stein 2015). However, the effects of etifoxine on muscle tone are still not clear. Despite the results of clinical studies, there is controversial evidence in the literature about the impact of etifoxine on spontaneous locomotor activity in animals (Schlichter et al. 2000; Girard et al. 2009; Verleye et al. 2009; Bourin and Hascoët 2010). In our previous experiments (Zagorchev et al. 2018) we reported a decrease of the direct single twitch response in isolated rat nerve-skeletal muscle preparations induced by etifoxine. In this article, we treat the problem with the influence of etifoxine on muscle tone and locomotor activity in vivo and the effects of etifoxine on striated muscle preparations under the conditions of indirect stimulation. These additional studies would make it possible to elucidate the impact of etifoxine on motor function and to provide data on a possible advantage of nonbenzodiazepine anxiolytic compound etifoxine over conventional benzodiazepine anxiolytics regarding the safety profile. 
Nifedipine is a selective L-type calcium channel blocker and a structural analogue of dihydropyridine. Many studies have been performed in order to investigate the effects of L-type calcium channel antagonists, including dihydropyridines, phenylalkylamines, and benzothiazepines on the muscular response. Electrophysiological studies have shown that these agents prevent the L-type calcium currents carried through the slow calcium channels $\left(\mathrm{Ca}_{\mathrm{v}} 1.1, \mathrm{Ca}_{\mathrm{v}} 1.2, \mathrm{Ca}_{\mathrm{v}} 1.3\right.$ and $\left.\mathrm{Ca}_{\mathrm{v}} 1.4\right)$ in vascular smooth muscle, cardiac and skeletal muscle. In addition, blockers of calcium influx augment the neuromuscular blockade induced by non-depolarizing or depolarizing muscle relaxants in isolated preparations and in intact animals (Salvador et al. 1988; Sekerci and Tulunay 1996).

Here we investigated the effects of the TSPO ligand etifoxine on muscle tone and locomotor activity in vivo. In order to elucidate the mechanism of action of etifoxine on the presynaptic membrane and neuromuscular junction, we also performed comparative in vitro studies on etifoxine and nifedipine on indirectly-elicited twitches of striated muscle preparations.

\section{Materials and Methods}

All experiments (in vivo and in vitro) were approved by the Bulgarian Food Safety Agency (approval number: 87/9.01.2014) and the Ethics Committee of the Medical University-Plovdiv, Bulgaria (approval number: 5/29.09.2016).

\section{In vivo experiments}

\section{Animals}

Thirty male Wistar rats (weight of 160-180 g) were divided into three groups $(n=10)$. Animals were treated intraperitoneally (i.p.) as follows: Group 1 with an equivalent volume $(0.1 \mathrm{ml} / 100 \mathrm{~g}$ b.w. $)$ of vehicle $(0.1 \%$ Tween 20 in $0.9 \% \mathrm{NaCl}$ solution) (Control); Group 2 with etifoxine in a dose of 50 $\mathrm{mg} / \mathrm{kg}$ b.w.; Group 3 with etifoxine in a dose of $100 \mathrm{mg} / \mathrm{kg}$ b.w. Rats were kept under standard laboratory conditions (temperature $24 \pm 2{ }^{\circ} \mathrm{C}$, humidity $50 \%$ and 12 -h dark/light cycle). The rodents received food and water ad libitum.

\section{Bar holding test}

The test was performed thirty minutes after treatment as described before (Zagorchev et al. 2016). Briefly, a metal bar ( $2 \mathrm{~mm}$ in diameter and $40 \mathrm{~cm}$ in length) was suspended above a soft surface. The distance between the surface and the bar was $40 \mathrm{~cm}$. The rat was held in a manner allowing its forearms to grasp the bar and the time spent on the bar was registered. The cutoff time was 120 seconds.

\section{Activity cage test}

The locomotor activity in rats was studied using an activity cage apparatus (Ugo Basile, Italy), equipped with horizontal and vertical sensors to allow automatic measurement of the animal movements. Immediately after the bar holding test, rats were placed into the appliance and allowed exploration for $5 \mathrm{~min}$. The total number of horizontal and vertical movements was recorded.

\section{In vitro striated muscle experiments}

\section{Animals and tissue preparations}

Abdominal tissue preparations (n. intercostalis - m. transversus abdominis) were obtained as previously described by Zagorchev et al. (2016). The muscle strips from male Wistar rats (160-200 g) were immersed and isometrically fixed in individual organ baths containing $15 \mathrm{ml}$ modified Krebs' solution maintained at $35.5 \pm 0.3^{\circ} \mathrm{C}$ and constantly aerated with $95 \% \mathrm{O}_{2}$ and $5 \% \mathrm{CO}_{2}$. The $\mathrm{pH}$ of the solution was kept at $7.28 \pm 0.08$. Preparations were allocated in the organ baths in a random manner.

Each strip was placed across two platinum electrodes connected to an electronic stimulator (EFS - PZ03, C-optic, Bulgaria). The initial tension applied on all preparations to achieve isometric recording was $7 \mathrm{mN}$.

Contractions were induced by indirect stimulation at a frequency of $5 \mathrm{~Hz}$ and supramaximal voltage of $80 \mathrm{~V}$ with $0.02 \mathrm{~ms}$ square-wave pulses. The extremely short pulse duration $(0.02 \mathrm{~ms})$ results in indirect (nerve) stimulation of the muscle tissue and typical neuromuscular activation.

The duration of the muscle stimulation was $3 \mathrm{~s}$, followed by a $7 \mathrm{~s}$ pause. The contraction force was registered by an isometric force transducer (TRI 201, LSi Letica; Panlab S.L., Barcelona, Spain) and recorded with a computer-based system. The employed experimental protocol was described previously (Ivanov et al. 2011). The interval of discretization was $1 \mathrm{~ms}$.

The preparations were allowed a 20 min period of equilibration before stimulation or addition of drugs. Initially, indirectly-elicited twitch contraction activity was obtained and this was stable in previously described conditions (control activity). After achieving this state, nifedipine and etifoxine were added separately to the organ baths.

Nifedipine was used at a concentration of $10^{-5} \mathrm{M}$. Nine concentrations of etifoxine $10^{-8}, 5 \cdot 10^{-8}, 10^{-7}, 7 \cdot 10^{-7}, 10^{-6}$, $5 \cdot 10^{-6}, 10^{-5}, 3 \cdot 10^{-5}$, and $10^{-4} \mathrm{M}$ were studied. Initially, the lowest concentration was added and a five-minute record of the twitch contractions was registered. The strips were washed out with Krebs solution (3-4 times) before adding a higher concentration of etifoxine. The effect of the studied concentrations on the contractile activity was evaluated about 25 min after the addition of the drugs to the bath. 
The concentration-effect curve of etifoxine on indirectlyelicited twitch tension was obtained and the mean $\mathrm{IC}_{50}$ value of etifoxine was calculated as the concentration required to produce $50 \%$ reduction in the force of the muscle twitches (the control twitch contraction activity was taken as 100\%).

The cut-off time of the experiments involving a single muscle strip was $45 \mathrm{~min}$ after the isolation.

\section{Drugs and solutions}

Etifoxine (Stresam ${ }^{\oplus} 50$ mg, distributed by Biocodex, Gentilly, France) was obtained from a pharmacy and suspended in $0.9 \% \mathrm{NaCl}$ containing $0.1 \%$ Tween 20 . Nifedipine was purchased from Sigma.

Composition of the preparation solution (in mmol/l): $\mathrm{Na}^{+}$ 143; $\mathrm{K}^{+}$5.84; $\mathrm{Ca}^{2+} 3.7$ and $\mathrm{Cl}^{-} 157$.

Composition of Krebs' solution (in mmol/l): $\mathrm{Na}^{+} 143 ; \mathrm{K}^{+}$ 5.84; $\mathrm{Ca}^{2+} 2.5 ; \mathrm{Mg}^{2+} 1.19 ; \mathrm{Cl}^{-} 133 ; \mathrm{HCO}_{3}{ }^{-} 16.7 ; \mathrm{H}_{2} \mathrm{PO}_{4}{ }^{-} 1.2$ and glucose 11.5.

\section{Statistical analysis}

The statistical analysis was performed using SPSS ver. 17. All data are presented as mean \pm SEM.

\section{In vivo experiments}

One sample Kolmogorov-Smirnov test was performed to verify the normal distribution. One-way analysis of variance (ANOVA) with Bonferroni Multiple Comparison Test was used in case of normal distribution. In case of non-normal distribution logarithmic transformation of the results was performed and distribution was rechecked. Non-parametric Two independent samples test (Mann-Whitney U test) was applied to analyze the results with non-normal distribution. Differences were considered significant at $p<0.05$.

\section{In vitro experiments}

One sample Kolmogorov-Smirnov test confirmed that all data has normal distribution. One-way ANOVA with Bonferroni Multiple Comparison Test and the Paired samples T-test were used for statistical analysis. The number of tested preparations is indicated by $n$. Differences were considered significant at $p<0.05$.

\section{Results}

In vivo evaluation of the muscle tone and locomotor activity in rats

Analyzing the results of bar holding test, we observed that etifoxine (50 and $100 \mathrm{mg} / \mathrm{kg}$ b.w., i.p.) did not significantly
Table 1. Effect of etifoxine on muscle tone evaluated by bar holding test

\begin{tabular}{lc}
\hline Group & Time $(\mathrm{s})$ \\
\hline Control & $98.10 \pm 14.6$ \\
Etifoxine50 & $108.79 \pm 11.21$ \\
Etifoxine100 & $91.91 \pm 10.24$ \\
\hline
\end{tabular}

Data are presented as mean \pm SEM; $n=10 . p>0.05 v s$. Control group (Mann-Whitney U test). Control, rats treated with an equivalent volume $(0.1 \mathrm{ml} / 100 \mathrm{~g}$ b.w. $)$ of vehicle $(0.1 \%$ Tween 20 in $0.9 \% \mathrm{NaCl}$ solution); Etifoxine 50 , rats treated with etifoxine in a dose of $50 \mathrm{mg} / \mathrm{kg}$ b.w.; Etifoxine100, rats treated with etifoxine in a dose of $100 \mathrm{mg} / \mathrm{kg}$ b.w.

affect the time spent by rats on the bar and the groups treated with the drug showed similar results to the Control group (Table 1).

Administration of etifoxine decreased the locomotor activity in a concentration-dependent manner, but no statistically significant difference was found when compared to the Control group (Table 2).

Table 2. Effect of etifoxine on locomotor activity evaluated with activity cage test

\begin{tabular}{lcc}
\hline Group & $\begin{array}{c}\text { Number of horizontal } \\
\text { movements }\end{array}$ & $\begin{array}{c}\text { Number of } \\
\text { vertical movements }\end{array}$ \\
\hline Control & $590.0 \pm 100.2$ & $97.1 \pm 24.1$ \\
Etifoxine50 & $502.3 \pm 42.8$ & $57.3 \pm 5.4$ \\
Etifoxine100 & $455.7 \pm 39.8$ & $47.7 \pm 10.8$ \\
\hline
\end{tabular}

Data are presented as mean \pm SEM; $n=10 . p>0.05 v s$. Control group (one-way ANOVA).

\section{In vitro studies on striated muscle preparations}

The effects of $10^{-5} \mathrm{M}$ nifedipine on indirectly-elicited twitch tension are shown in Figure 1. Following $24 \mathrm{~min}$ exposure, nifedipine reduced the twitch tension in comparison to the control value $(2.5 \pm 1.1 \mathrm{mN}$ vs. $5.2 \pm$ $1.0 \mathrm{mN}, p<0.05)$.

In all tested concentrations $\left(10^{-8}-10^{-4} \mathrm{M}\right)$ etifoxine had no significant effect on indirectly-elicited twitch tension. The most prominent reduction in the muscle contractions was detected at high concentrations of etifoxine $\left(3 \cdot 10^{-5} \mathrm{M}\right.$ and $\left.10^{-4} \mathrm{M}\right)$. However, even under these conditions no significant difference was found in comparison to the control tension (Fig. 2). We failed to detect statistically significant difference also between the results obtained at different concentrations of etifoxine.

The mean $\mathrm{IC}_{50}$ value of etifoxine-induced reduction of indirectly-elicited twitch tension could not be calculated at 


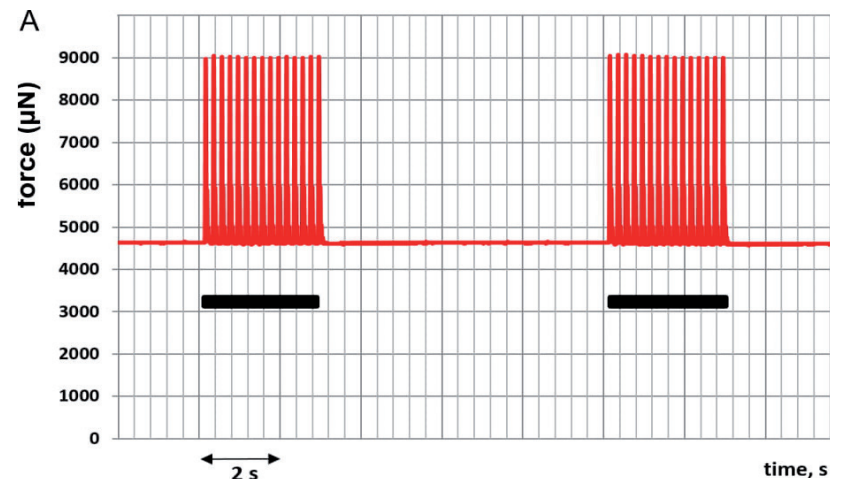

C

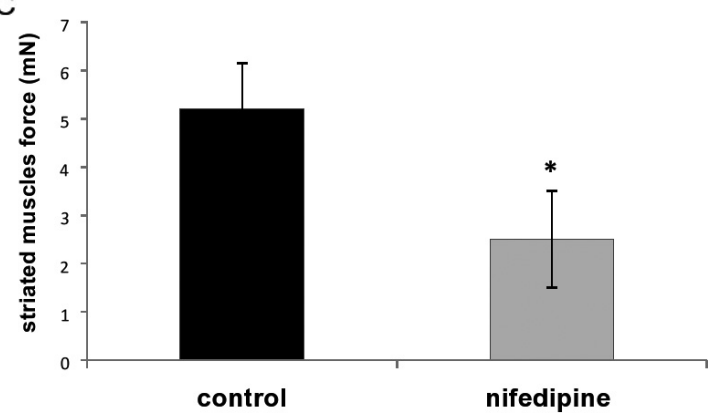

concentration range $10^{-8}-10^{-4} \mathrm{M}$, its value may be found at concentrations higher than $10^{-4} \mathrm{M}$ (Figure 2).

As shown in Figure $3,10^{-6} \mathrm{M}$ etifoxine and $10^{-5} \mathrm{M}$ etifoxine did not produce a significant reduction in the muscle force when compared to the control $(6.4 \pm 1.0 \mathrm{mN} v s .6 .5 \pm$ $0.8 \mathrm{mN}, p>0.05 ; 5.6 \pm 0.7 \mathrm{mN}$ vs. $5.8 \pm 0.7 \mathrm{mN}, p>0.05$, respectively).

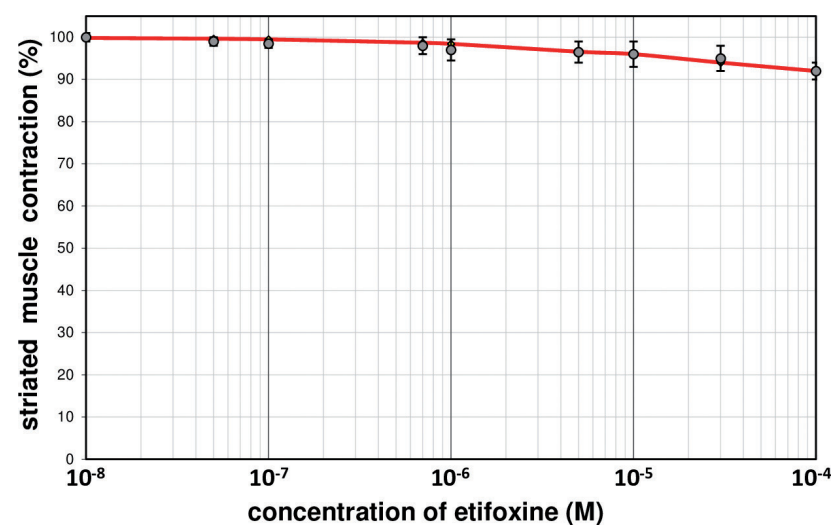

Figure 2. Concentration-response curve of $10^{-8}-10^{-4} \mathrm{M}$ etifoxine on twitch contractions of isolated rat abdominal striated muscle strips ( 25 min after addition). Stimulus parameters: $5 \mathrm{~Hz}, 20 \mu \mathrm{s}$, $80 \mathrm{~V}$. Each point is calculated as mean \pm SEM of eight preparations.

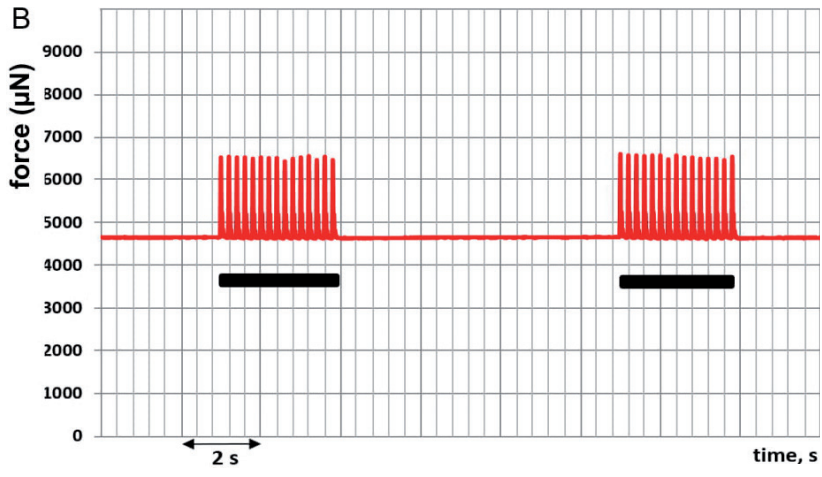

Figure 1. Effect of nifedipine on indirectly-elicited twitch contractions of rat abdominal preparations. The stimulus parameters were: $5 \mathrm{~Hz}, 80 \mathrm{~V}$ (supramaximal), and $20 \mu \mathrm{s}$ square-wave pulse duration. The bold black line represents the duration of the stimulus. A. Control twitch response. B. Contractility in presence of $10^{-5} \mathrm{M}$ nifedipine (24 min after addition). C. Bar chart, representing the decrease in the twitch tension $24 \mathrm{~min}$ after addition of $10^{-5} \mathrm{M}$ nifedipine. ${ }^{*} p<0.05 v$ s. control (paired T-test); $n=9$.

\section{Discussion}

In vivo evaluation of the muscle tone and locomotor activity in rats

Acording to Bourin and Hascoët (2010), acute intraperitoneal administration of etifoxine in doses $60 \mathrm{mg} / \mathrm{kg}$ and $75 \mathrm{mg} / \mathrm{kg}$ induces a sedative effect and decreases significantly spontaneous locomotor activity in the actimeter test in mice. Lower doses of etifoxine $(25,40$ and $50 \mathrm{mg} / \mathrm{kg})$ do not influence the spontaneous locomotor activity (Schlichter et al. 2000; Bourin and Hascoët 2010). Our results obtained from activity cage test show that etifoxine $(50 \mathrm{mg} / \mathrm{kg})$ reduces the number of horizontal and vertical movements 30 min after i.p. administration. However, the values did not reach statistical significance (Table 2), and this observation is in accordance with Bourin and Hascoët (2010). Similar results were obtained when using a higher dose of the drug $(100 \mathrm{mg} / \mathrm{kg})$ in contrast to the report of the same authors. The explanation more likely lay in the different species (rats $v s$. mice) and appliances (activity cage $v s$. actimeter test) used for the experiments.

Moreover, our results are consistent with those of Girard et al. (2009). These authors reported that oral administration of $2 \times 10 \mathrm{mg} / \mathrm{kg}, 2 \times 25 \mathrm{mg} / \mathrm{kg}$ and $2 \times 50 \mathrm{mg} / \mathrm{kg}$ per day etifoxine had no effect on locomotor activity of intact rats recorded in an Opto-Varimex apparatus (Girard et al. 2009). Verleye and co-authors also registered that etifoxine at $25 \mathrm{mg} / \mathrm{kg}$ and $50 \mathrm{mg} / \mathrm{kg}$ doses (i.p.) did not modify spon- 
taneous locomotor activity determined by rotarod test in mice (Verleye et al. 2009).

In addition, our results obtained with bar holding test confirm that etifoxine in doses $50 \mathrm{mg} / \mathrm{kg}$ and $100 \mathrm{mg} / \mathrm{kg}$ i.p. does not reduce the muscle tone of intact rats (Table 1). A possible explanation of the lack of myorelaxation after etifoxine administration is related to the fact that the drug does not bind to the $\mathrm{GABA}_{\mathrm{A}}$ receptor complex subunits responsible for muscle tone reduction. It has been suggested that benzodiazepines binding to a 2 subunit of the $\mathrm{GABA}_{\mathrm{A}}$ receptors results in reduced muscle tone (Crestani et al. 2001), while a 3 subunit of the same receptor contributes to the same effect at high concentrations of benzodiazepines (Möhler et al. 2001). Another study found evidence of the role of $\alpha 1, \alpha 2, \alpha 3$ and $\alpha 5$ subunits in diazepam-induced myorelaxation (Luscher et al. 2012). However, etifoxine was found to bind to $\beta 2$ or $\beta 3$ subunits of the $\mathrm{GABA}_{\mathrm{A}}$ receptor complex and to our knowledge, these subunits are not involved in muscle tone reduction (Hamon et al. 2003).

Etifoxine evokes increased biosynthesis of neurosteroids through activation of translocator protein $18 \mathrm{kDa}$ (TSPO) formerly termed peripheral-type benzodiazepine receptor (PBR). These neurosteroids and benzodiazepines bind to different sites of the $\mathrm{GABA}_{\mathrm{A}}$ receptors (Rupprecht et al. 2010; Gunn et al. 2011). Another study found evidence that selective TSPO ligands with low affinity to central-type benzodiazepine receptor (CBR) do not induce myorelaxation (Zhang et al. 2014). It is therefore quite possible, that

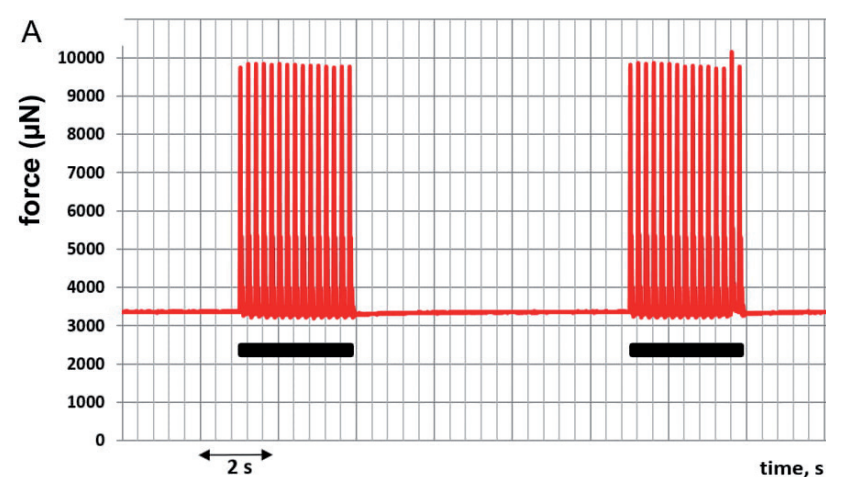

C

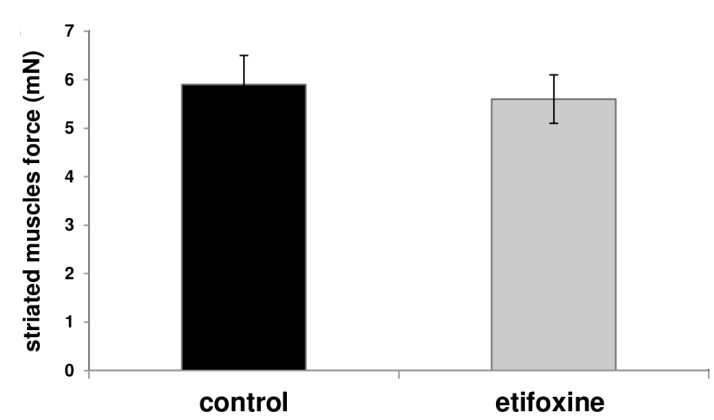

the activation of PBR is not associated with a reduction in muscle tone and motor impairment, which also could be concluded from our experiments with the TSPO ligand etifoxine.

\section{In vitro studies on striated muscle preparations}

To elucidate the mechanism of the influence of etifoxine on striated muscle contraction we compared its effects to those of nifedipine - a selective L-type calcium channel blocker.

Previously, we reported that $10^{-5} \mathrm{M}$ nifedipine significantly decreases the muscle force of striated muscle preparations following direct stimulation (Zagorchev et al. 2018). Our recent experiments revealed the same outcome during indirect stimulation (Fig. 1). Furthermore, the inhibitory effects of nifedipine on muscle contractions during nerve (indirect) activation are more prominent than the ones obtained with muscle (direct) stimuli.

There are contradictory data in the literature regarding the influence of calcium antagonists on neuromuscular activity. Rodrigues de Sousa and co-authors reported that $10^{-5} \mathrm{M}$ nifedipine did not produce significant decrease in the muscular response to indirect electric stimulation (Rodrigues de Sousa et al. 2006). However, our results are similar to the ones observed by other researchers. In contrast to Rodrigues de Sousa et al. (2006), Del Pozo and Baeyens (1986) studied the effects of nifedipine $(0.001-0.5 \mathrm{mM})$, verapamil and diltiazem on rat's phrenic-nerve diaphragm preparations and reported

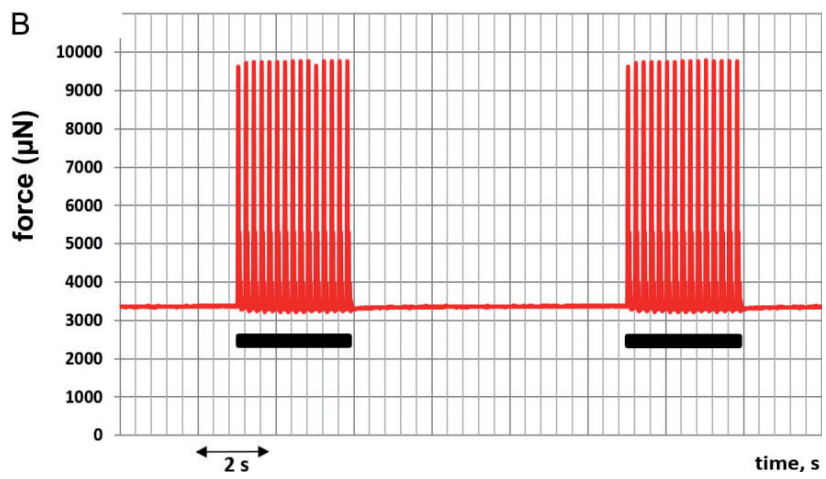

Figure 3. Effects of etifoxine on indirectly-elicited twitch contractions of isolated rat abdominal preparations. Stimulus parameters: $5 \mathrm{~Hz}, 20 \mu \mathrm{s}, 80 \mathrm{~V}$. The bold black line represents the duration of the stimulus. A. Control twitch response. B. Contractility in presence of $10^{-6} \mathrm{M}$ etifoxine (25 min after addition). C. Bar chart to compare the response $25 \mathrm{~min}$ after $10^{-5} \mathrm{M}$ etifoxine addition. Statistic: paired T-test; $n=9$. 
a concentration-dependent reduction in the contractile response to indirect stimulation. Similar results were also observed in other experimental studies using calcium channel blockers (Kraynack et al. 1983; Salvador et al. 1988; Sekerci and Tulunay 1996).

It is highly possible that the reduction of the contractile activity registered in this our study is related to the effect of nifedipine on the nerve cell (prejunctional action) and on the muscle cell membrane (postjunctional action). Electrophysiological studies performed by Rodrigues de Sousa et al. (2006) show presynaptic action of $10^{-5} \mathrm{M}$ nifedipine. The concentration of ionized calcium $\left(\mathrm{Ca}^{2+}\right)$ in the extracellular fluid is an essential factor for neuromuscular transmission. In the absence of $\mathrm{Ca}^{2+}$, depolarization of the neuronal membrane (e.g. by electrical stimulation) will not lead to the release of neurotransmitters (Martyn et al. 2009). A lot of studies performed in vivo and in vitro showed that calcium channel blockers prevent the calcium entry through the calcium slow channels in the presynaptic membrane. Thus, the mobilization of acetylcholine in the motor nerve terminal and its release are impaired. This results in inhibited neuromuscular transmission and muscular contraction (Kraynack et al. 1983; Sekerci and Tulunay 1996). Probably the most critical role in the process is played by L-type $\mathrm{Ca}^{2+}$-channels $\left(\mathrm{Ca}_{\mathrm{v}} 1.2\right.$ and $\left.\mathrm{Ca}_{\mathrm{v}} 1.3\right)$ localized on the neuronal cell bodies and dendrites (Catterall et al. 2005). Furthermore, calcium channel blockers have local anesthetic activity that may contribute to the inhibitory effect on muscle contraction, probably due to the blockade of voltage-gated $\mathrm{Na}^{+}$-channels and reduced sodium influx through ion channels in the neuronal membrane (Sekerci and Tulunay 1996). And last but not least in the conditions of nerve stimulation muscle activation is also possible. Nifedipine could inhibit the $\mathrm{Ca}_{\mathrm{v}} 1.1$ L-type calcium channels in sarcolemma that play role in excitation-contraction coupling. The blockage of $\mathrm{Ca}_{\mathrm{v}} 1.1$ L-type calcium channels in the muscle cell membrane by nifedipine could contribute to its inhibitory effect on muscle contraction during nerve stimulation. Since the inhibitory effect of nifedipine on muscle contraction is more pronounced in conditions of nerve activation (current results) than in muscle stimuli (previous data), nifedipine may have more potent prejunctional action than postjunctional effect.

Here we report that etifoxine, unlike nifedipine, has insignificant effect on the indirectly-elicited twitch contractions. These results obtained with in vitro experiments are confirmed by the tests performed in vivo, which also detected lack of myorelaxant effect of etifoxine in doses 50 and 100 $\mathrm{mg} / \mathrm{kg}$ in rats.

Our search of the literature returned no results related to the use of etifoxine in this type of neuromuscular preparations. Nevertheless, there are some reports about the effects of other TSPO agonists on neuromuscular synapse, which are consistent with our results for the TSPO ligand etifoxine. In vitro experiments indicate that Ro5-4864 (selective TSPO agonist) has no effect on the neuromuscular transmission in mouse isolated phrenic nerve-diaphragm preparations (Chiou and Chang 1994).

Based on our in vitro studies on neuromuscular preparations (rat $\mathrm{n}$. intercostalis - $\mathrm{m}$. transversus abdominis), it can be concluded that etifoxine does not impair the impulse transmission in the neuromuscular synapse and does not reduce the muscle tone. During indirect (nerve) stimulation, the influence of etifoxine on L-type $\mathrm{Ca}^{2+}$-channels on the neuronal membrane is insignificant.

Analyzing the experimental results obtained for the influence of etifoxine on striated muscle contraction, the question about the mechanism of these effects is raised.

Allopregnanolone, one of the neurosteroids synthesized after binding of etifoxine to TSPO, is known to reduce neuronal excitability by inhibiting L-type voltage-gated calcium channels. However, such effect was registered at much higher concentrations than the level of allopregnanolone produced from progesterone in the brain so they have no clinical application (Uzunova et al. 1998; Earl 2011; Earl and Tietz 2011).

Summarizing the literature data and the results we have found, we can conclude that, unlike nifedipine, etifoxine does not have a presynaptic action. The lack of statistically significant reduction of striated muscle contractility following indirect stimulation in the presence of etifoxine proves the absence of competitive antagonism between etifoxine and the neurotransmitter acetylcholine.

In summary, the TSPO ligand etifoxine has no myorelaxant effect, which is an advantage over the conventional benzodiazepine anxiolytics. The activation of TSPO is not associated with reduction in muscle tone and motor impairment. Etifoxine does not affect the presynaptic membrane and its influence on L-type $\mathrm{Ca}^{2+}$-channels is insignificant. Etifoxine does not act as a competitive antagonist of acetylcholine. Our in vitro and in vivo experiments show that etifoxine, similar to other TSPO ligands, does not impair the impulse transmission in the neuromuscular junction (e.g. in abdominal muscles).

\section{References}

Aleksandrovsky YA, Krasnov VN, Neznanov NG, Romasenko LV (2010): Efficacy of etifoxine versus phenazepam in treatment of patients with adjustment disorders (open-label randomized controlled trial). Russian Psychiatric Journal. Therapy of the mentally ill. 1, 74-78

Bourin M, Hascoët M (2010): Implication of 5-HT2 receptor subtypes in the mechanism of action of the GABAergic compound etifoxine in the four-plate test in Swiss mice. Behav. Brain Res. 208, 352-358 
https://doi.org/10.1016/j.bbr.2009.11.046

Catterall WA, Perez-Reyes E, Snutch TP, Striessnig J (2005): International Union of Pharmacology. XLVIII. Nomenclature and structure-function relationships of voltage-gated calcium channels. Pharmacol. Rev. 57, 411-425 https://doi.org/10.1124/pr.57.4.5

Chiou LC, Chang CC (1994): Pharmacological relevance of peripheral type benzodiazepine receptors on motor nerve and skeletal muscle. Br. J. Pharmacol. 112, 257-261 https://doi.org/10.1111/j.1476-5381.1994.tb13060.x

Crestani F, Low K, Keist R, Mandelli M, Möhler H, Rudolph U (2001): Molecular targets for the myorelaxant action of diazepam. Mol. Pharmacol. 59, 442-5 https://doi.org/10.1124/mol.59.3.442

Del Pozo E, Baeyens JM (1986): Effects of calcium channel blockers on neuromuscular blockade induced by aminoglycoside antibiotics. Eur. J. Pharmacol. 128, 49-54 https://doi.org/10.1016/0014-2999(86)90556-X

Earl D (2011): Regulation of neuronal L-type voltage-gated calcium channels by Flurazepam and other positive allosteric GABAA receptor modulators. Theses and dissertations. Paper 566

Earl D, Tietz E (2011): Inhibition of recombinant L-type voltagegated calcium channels by positive allosteric modulators of GABAA receptors. J. Pharmacol. Exp. Ther. 337, 301-311 https://doi.org/10.1124/jpet.110.178244

Girard PH, Pansart Y, Gillardin JM (2009): Preventive and curative effects of etifoxine in a rat model of brain oedema. Clin. Exp. Pharmacol. Physiol. 36, 655-661 https://doi.org/10.1111/j.1440-1681.2008.05127.x

Gunn BG, Brown AR, Lambert JJ, Belelli D (2011): Neurosteroids and $\operatorname{GABA}(\mathrm{A})$ receptor interactions: a focus on stress. Front Neurosci. 5, 131 https://doi.org/10.3389/fnins.2011.00131

Hamon A, Morel A, Hue B, Verleye M, Gillardin JM (2003): The modulatory effects of the anxiolytic etifoxine on GABA(A) receptors are mediated by the beta subunit. Neuropharmacology $45,293-303$ https://doi.org/10.1016/S0028-3908(03)00187-4

Ivanov I, Nikolova S, Aladjov D, Stefanova I, Zagorchev P (2011): Synthesis and contractile activity of substituted 1,2,3,4- tetrahydroisoquinolines. Molecules 16, 7019-7042 https://doi.org/10.3390/molecules16087019

Kraynack BJ, Lawson NW, Gintautas J (1983): Neuromuscular blocking action of verapamil in cats. Can. Anaesth. Soc. J. 30, 242-247 https://doi.org/10.1007/BF03013802

Luscher BP, Baur R, Goeldner M, Sigel E (2012): Influence of GABA(A) receptor alpha subunit isoforms on the benzodiazepine binding site. PLoS One 7, e42101 https://doi.org/10.1371/journal.pone.0042101

Martyn JA, Fagerlund MJ, Eriksson LI (2009): Basic principles of neuromuscular transmission. Anaesthesia 64, 1-9 https://doi.org/10.1111/j.1365-2044.2008.05865.x

Micallef J, Soubrouillard C, Guet F, Le Guern ME, Alquier C, Bruguerolle B, Blin O (2001): A double blind parallel group placebo controlled comparison of sedative and mnesic effects of etifoxine and lorazepam in healthy subjects [corrected]. Fundam. Clin. Pharmacol. 15, 209-216 https://doi.org/10.1046/j.1472-8206.2001.00025.x

Möhler H, Crestani F, Rudolph U (2001): GABA(A)-receptor subtypes: a new pharmacology. Curr. Opin. Pharmacol. 1, 22-25 https://doi.org/10.1016/S1471-4892(01)00008-X

Nguyen N, Fakra E, Pradel V, Jouve E, Alquier C, Guern Le M, Micallef J, Blin O (2006): Efficacy of etifoxine compared to lorazepam monotherapy in thetreatment of patients with adjustment disorders with anxiety: a double-blind controlled study in general practice. Hum. Psychopharmacol. 21, 139-149 https://doi.org/10.1002/hup.757

Rodrigues de Sousa S, Braga A, Potério G, Braga F, Loyola Y, Fernandes S (2006): Influence of nifedipine on the neuromuscular block produced by atracurium and cistracurium. Study in rat phrenic-diaphragmatic nerve preparation. Rev. Bras. Anestesiol. 56, 157-167 https://doi.org/10.1590/S0034-70942006000200007

Rupprecht R, Papadopoulos V, Rammes G, Baghai TC, Fan J, Akula N, Groyer G, Adams D, Schumacher M (2010): Translocator protein $(18 \mathrm{kDa})$ (TSPO) as a therapeutic target for neurological and psychiatric disorders. Nat. Rev. Drug Discov. 9, 971-88 https://doi.org/10.1038/nrd3295

Salvador A, del Pozo E, Carlos R, Baeyens JM (1988): Differential effects of calcium channel blocking agents on pancuronium and suxamethonium-induced neuromuscular blockade. Br. J. Anaesth. 60, 495-499 https://doi.org/10.1093/bja/60.5.495

Schlichter R, Rybalchenko V, Poisbeau P, Verleye M, Gillardin J (2000): Modulation of GABAergic synaptic transmission by the non-benzodiazepine anxiolytic etifoxine. Neuropharmacology 39, 1523-1535 https://doi.org/10.1016/S0028-3908(99)00253-1

Sekerci S, Tulunay M (1996): Interactions of calcium channel blockers with non-depolarising muscle relaxants in vitro. Anaesthesia 51, 140-144

https://doi.org/10.1111/j.1365-2044.1996.tb07701.x

Servant D, Graziani PL, Moyse D, Parquet PJ (1998): Treatment of adjustment disorder with anxiety: efficacy and tolerance of etifoxine in a double blind controlled study. Encephale 24, 569-574

Stein D (2015): Etifoxine versus alprazolam for the treatment of adjustment disorder with anxiety: a randomized controlled trial. Adv. Ther. 32, 57-68 https://doi.org/10.1007/s12325-015-0176-6

Uzunova V, Sheline Y, Davis JM, Rasmusson A, Uzunov DP, Costa E, Guidotti A (1998): Increase in the cerebrospinal fluid content of neurosteroids in patients with unipolar major depression who are receiving fluoxetine or fluvoxamine. Proc. Natl. Acad. Sci. USA 95, 3239-3244 https://doi.org/10.1073/pnas.95.6.3239

Verleye M, Heulard I, Gillardin J (2009): The anxiolytic etifoxine protects against convulsant and anxiogenic aspects of the alcohol withdrawal syndrome in mice. Alcohol. 43, 197-206 https://doi.org/10.1016/j.alcohol.2009.02.003

Zagorchev P, Apostolova E, Kokova V, Peychev L (2016): Activation of KCNQ channels located on the skeletal muscle membrane by retigabine and its influence on the maximal muscle force in rat muscle strips. Naunyn Schmiedebergs Arch. Pharmacol. 389, 439-446 https://doi.org/10.1007/s00210-016-1211-0 
Zagorchev P, Kokova V, Apostolova E, Peychev L (2018): Possible role of $18-\mathrm{kDa}$ translocator protein (TSPO) in etifoxine-induced reduction of direct twitch responses in isolated rat nerve-skeletal muscle preparations. Trop. J. Pharmaceut. Res. 17, 1309-1315 https://doi.org/10.4314/tjpr.v17i7.12

Zhang LM, Zhao N, Guo WZ, Jin ZL, Qiu ZK, Chen HX, Xue R, Zhang YZ, Yang RF, Li YF (2014): Antidepressant-like and anxiolytic-like effects of YL-IPA08, a potent ligand for the translocator protein $(18 \mathrm{kDa})$. Neuropharmacology 81, 116-125

https://doi.org/10.1016/j.neuropharm.2013.09.016

Received: June 17, 2019

Final version accepted: November 15, 2019 